\title{
Aa.Vv., Crises de vers
}

\section{Luc Fraisse}

\section{(2) OpenEdition}

\section{Journals}

\section{Édition électronique}

URL : https://journals.openedition.org/studifrancesi/37832

DOI : 10.4000/studifrancesi.37832

ISSN : 2427-5856

\section{Éditeur}

Rosenberg \& Sellier

\section{Édition imprimée}

Date de publication : 15 décembre 2004

Pagination : 621

ISSN : 0039-2944

\section{Référence électronique}

Luc Fraisse, «Aa.VV., Crises de vers », Studi Francesi [En ligne], 144 (XLVIII | III) | 2004, mis en ligne le 30 novembre 2015, consulté le 08 mai 2021. URL : http://journals.openedition.org/studifrancesi/37832 ; DOI : https://doi.org/10.4000/studifrancesi.37832

\section{Ce document a été généré automatiquement le 8 mai 2021.}

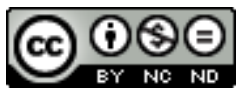

Studi Francesi è distribuita con Licenza Creative Commons Attribuzione - Non commerciale - Non opere derivate 4.0 Internazionale. 


\section{Aa.Vv., Crises de vers}

\section{Luc Fraisse}

\section{RÉFÉRENCE}

AA.VV., Crises de vers, «Lieux littéraires/ La Revue», $n^{\circ}$ 1, juin 2000, Montpellier, Université Paul-Valéry, pp. 316

1 Voici le premier numéro d'une revue créée à l'initiative du Centre d'études romantiques et dix-neuviémistes de l'Université Paul-Valéry à Montpellier; La Revue est à distinguer de la collection d'ouvrages «Lieux littéraires», publiée à Saint-Étienne aux éditions des Cahiers intempestifs. Chaque numéro, ainsi que l'annonce en préambule Alain VAILLANT, comprendra un cahier central sur une question de littérature; une rubrique «recherches en chantier» rendant compte de travaux en cours d'étudiants; un dossier de recherche mettant l'accent sur des points de méthode, de vie institutionnelle, de définitions épistémologiques.

2 Ici, le dossier central, intitulé "Crises de vers», comporte une étude de Serge Zenkine, «Culture versus rhétorique: la poésie de Victor Hugo et de Théophile Gautier» (pp. 9-30) qui met l'accent sur le conflit profond, au XIX ${ }^{e}$ siècle, entre le principe rhétorique et un principe culturel posant au contraire la pluralité et l'hétérogénéité des choses de l'esprit. La confrontation de deux compagnons d'armes dans les batailles littéraires, l'auteur de «Canaris» (1828) dans Les Orientales et celui de «Bûchers et tombeaux» dans Émaux et camées (pré-originale, 1858) montre comment l'effort rationalisant et herméneutique de la vision rhétorique affronte cette dispersion hétérogène propre à la vision romantique. Philippe MARTY propose une «Poétique du dimanche» (pp. 31-71) où l'on trouve évoqué De la célébration du dimanche (1829) de Proudhon à côté de Chateaubriand, et mises en rapport la poétique des nombres et la poésie du XIX ${ }^{\mathrm{e}}$ siècle, notamment chez Hugo et Lamartine.

3 Le dossier "Questions à la recherche dix-neuviémiste» comporte une étude d'Alain VAILLANT, «Copernic, la littérature et le XIX ${ }^{\mathrm{e}}$ siècle» à la fin de laquelle est proposée (pp. 182-185) une série de mises en rapports précis entre la littérature du XIX ${ }^{e}$ siècle et la 
recherche littéraire aujourd'hui. Philippe RÉGNIER, dans «Thèses pour la discipline qui s'intitule 'littérature'«(pp. 187-201), définit la nouvelle place que tend à occuper le XIX siècle depuis qu'il n'est plus pour nous «le siècle dernier». Dans «Le goût du texte» (pp. 233-244), Stéphane VAcHon situe la place du XIX ${ }^{\mathrm{e}}$ siècle dans les méthodes du lansonisme, depuis que Jean-Jacques Ampère, à partir de 1830, avait instauré un débat entre les deux critères de l'étude et du goût pour aborder la littérature. Le critique note une réévaluation de l'écrivain dans les études dix-neuviémistes les plus récentes, visible dans la multiplication des biographies et la publication de vastes correspondances. Il relève dans ce champ la place significative de Balzac, installé «au cœur de la concurrence entre une économie du manuscrit et une économie du livre» (p. 241).

4 La dernière rubrique, "Chantiers en cours», revient à Balzac dans une étude intitulée «Séraphîta, Louis Lambert, Raphaël de Valentin, miroirs obliques de Janus» (pp. 263-274) où Cécile DheILy examine la dualité de ces trois œuvres. La dualité structure, on le sait, l'univers balzacien; elle tente un moment de se résoudre dans la neutralité, mais le plus souvent se dédouble au contraire à l'infini: ainsi le personnage balzacien se détermine-t-il à la faveur de croisement de séries, car plus il recherche l'unité, plus il voit s'ouvrir devant lui des clivages. Mais l'essentiel est sans doute que, chez Balzac, la dualité oppose moins des valeurs qu'elle ne multiplie le phénomène littéraire de la représentation. 